\title{
Fostering a Culture of Reading through School Libraries: Room to Read's Experience in India
}

\author{
Sunisha Ahuja \\ Asia Regional Program Director \\ Room to Read \\ India \\ Ami Ehrlich \\ Global Program Officer, Reading Room \\ Room to Read \\ United States \\ Julie Maurin \\ Programs Consultant \\ Room to Read \\ United States
}

\begin{abstract}
Since 2003, Room to Read, an international education NGO, has been working in India to help foster a culture of reading in schools through the establishment of over 1500 school libraries. This paper outlines the evolution Room to Read's Reading Room program in India as an example of how school library programs can address the reading challenges of children in developing countries. The focus of the paper is on Room to Read India's Primary Reading Enhancement Program (PREP), which will be piloted in the Reading Room program in 2008. The goal of PREP is to have a significant impact on the way reading is taught in primary schools in India. Details are provided on the approach, materials, activities, parent and community participation, government participation, and student assessments that make up the core components of the PREP design.
\end{abstract}

Keywords: libraries, culture of reading, Room to Read, India

\section{Introduction}

School libraries have a critical role to play in the development of a reading culture. Room to Read's five years of experience with the Reading Room program in India has not only confirmed this notion, it has also helped identify some of the key components necessary to ensure libraries are able to stimulate this culture of reading in all students. Libraries must take an adaptive, integrated approach with schools, not only by providing a physical library, but also ensuring these libraries are flexible enough to fit the school's particular context. It is essential to train librarians and teachers on managing and utilizing the library, work closely with the government, engage with parents and community, and ensure that teachers have the necessary tools and capacity to successfully utilize library resources to teach reading.

The purpose of this paper is to outline some of the major challenges facing the creation of a reading culture in India, and how Room to Read's programs have evolved over time to meet 
these challenges. It is important to note that this is not intended as a prescription, but rather as an example of one organization's experiences.

\section{Room to Read Background}

Since 2000, Room to Read has partnered with communities and governments in Asia and Africa to address the lack of school libraries in developing countries. Room to Read's Reading Room program provides children with access to appropriate, creative, relevant and interesting children's literature by establishing libraries in primary and secondary schools. Room to Read began its efforts by donating local language and English books to schools in need of reading resources. Since then, Room to Read has developed a holistic library program that provides three years of support, including books, educational materials, furniture and training to schools in Cambodia, Laos, India, Nepal, Sri Lanka, Vietnam, South Africa and Zambia.

It is widely recognized that access to supplemental reading materials is essential for literacy acquisition and retention. In well-resourced communities, these materials are usually available in schools, homes and libraries. However, there is a dearth of resources in the majority of poor communities, particularly in developing countries, and the majority of the children in these communities are not exposed to print materials in their schools or homes. Books are expensive, difficult to find, and if they do exist, are not relevant to the children's lives. Children are often limited to the monotony of outdated textbooks, which rarely inspire children to engage with books in a meaningful way. Children and their teachers do not have access to supplementary reading materials such as story books and updated non-fiction books that stimulate the imagination and encourage reading outside the classroom.

In many countries, school libraries fill this gap by providing free access to supplementary reading materials for children. These libraries are an important component of a complete education, and have a variety of demonstrated positive impacts on education, including higher scores on standardized tests, improved vocabulary and grammar, and positive attitudes towards reading (Lonsdale: 2003). Despite these findings, school libraries are often a low priority for school systems around the world that struggle with daunting issues such as shortages of qualified teachers and overcrowded classrooms. In fact, the 2000 UNESCO Education for All assessment revealed that school libraries were the lowest priority in educational spending (Krolak: 2005).

Given the potential impact that libraries can have on the quality of education, Room to Read is committed to ensuring that school libraries receive intellectual and financial attention. After establishing over 5,000 libraries in eight countries, Room to Read has found that it is imperative to provide access to books in ways that are adaptable and applicable to the needs and constraints of under-resourced schools in a wide variety of contexts around the world. When possible, Room to Read works with the school to set up a library in a separate room with traditional library management systems. However, the unfortunate reality is that many schools do not have a separate room to set aside for a library given issues of overcrowding, a dedicated librarian, and/or the ability to allocate a library period in the school schedule. So, Room to Read has introduced schools and communities to alternative methods of book provision, including mobile cart libraries and classroom libraries, which have been shown to be excellent alternatives to "formal libraries" (Krolak: 2005, Rosenberg: 1998). 
As the Reading Room program continues to evolve, Room to Read is committed to working with each country to develop flexible library programs that have an impact on children's learning. The program specifics in each country will depend on context-specific needs, opportunities and constraints.

This paper will focus on the Reading Room program in India, where Room to Read has worked since 2003 with schools, communities and the government to develop a library program that works in urban slum schools and rural schools. Through its Reading Room program, Room to Read India has provided children in marginalized communities access to books, supported teachers in using those books effectively, and is currently developing an early grade reading program that will further the development of the "culture of reading" in schools and communities.

\section{Education in India}

Since the 1950s, India has experienced many notable educational improvements. Primary enrollment rates have increased from less than one-third of children enrolled, to over threequarters of children in school. Since 2001, drop-out rates and gender disparity rates have both fallen by nearly $10 \%$. Like many countries worldwide, India has responded to the Education for All movement with a number of initiatives, and is successfully ushering children into the classroom. These efforts have resulted in increases to access and enrollment at the primary level, improvements in physical infrastructure at the school level, and teacher availability at school.

While progress has been made, schools in India continue to face very basic issues in providing equitable education to all children. Urban slum schools in Delhi and other large cities are overcrowded. Rural government schools often have only one or two classrooms that are in poor condition. Most urban and rural government schools lack basic resources such as textbooks and furniture, and teachers continue to rely on outdated instruction methods. The country is facing the reality that rapid expansion of enrollment strains the education system, threatening its quality.

Currently, over half of Indian children drop out at the primary school stage, and only half of enrolled students regularly attend classes in some of the northern states. In 2006, The National Council of Education Research and Training (NCERT) revealed low achievement scores across subject-based tests, and the Annual Status of Education (ASER) report in 2006 shows one-third of students in Standard VI cannot read at a Standard II level. The ASER data confirms that children are falling behind in their first two years of primary schooling.

The low achievement levels in primary schools can be attributed to several factors, including minimal investment in pre-primary education and socio-economic conditions. The largest government pre-primary program is the Integrated Child Development Scheme, which enrolls less than $20 \%$ of pre-primary aged children and lacks a solid curriculum, learning materials and effective staff. Therefore, children arrive in primary school with no foundation in preliteracy skills. A majority of these young students are first-generation learners with no academic support at home. Many come from marginalized or tribal communities or scheduled castes, and when they arrive in school at grade one, they are already at a learning disadvantage. 
As grade one and two enrollments comprise almost half of the total school enrollment, the stakes are high and the rewards great for "getting it right" in the first few years of schooling. From the early 1990s until now, the Government of India has experimented with a number of 'learning improvement programs'. The Minimum Levels of Learning approach was the first of such programs and attempted to establish a competency-based curriculum. In the late 1990s, curriculum revisions and teacher training programs such as the District Primary Education Program were guided by a 'child-centered, activity-based teaching' methodology, but showed little gains in learning.

The government is currently implementing a national effort to universalize elementary education called Sarva Shiksha Abhiyan (SSA), which was first launched during the 20002001 school year. The main focus of this initiative is to improve the quality of education, as demonstrated through an increase in learning outcomes. Under this program, states can now include an additional $2 \%$ of their total budget for supporting initiatives that focus on quality education initiatives. The Ministry is promoting the use of these funds for reading enhancement programs. Some states are unsure about how to effectively spend these funds, providing an opportunity for outside organizations to help guide this spending and partner with state governments to bolster their reading programs.

The government's emphasis on learning outcomes has spawned a variety of state-level 'learning enhancement' programs. Most states have now realized that the low learning outcomes in later primary or upper primary grades are a direct result of the inadequate language skills developed in the early primary grades. As the language deficit continues to mount with each grade and texts become denser and more abstract, poor language skills prove to be the biggest constraint for learning. Assam's Bidyajyoti Program and Andhra Pradesh's Children's Language Improvement program (CLIP) and Children's Learning Acceleration Program for Sustainability (CLAPS) address reading development in early grades. These programs emphasize reading skills as part of an overall framework for language development that is crucial for improving learning and thinking.

State-level programs such as CLIP and CLAPS are promising, but further efforts are needed to address a challenge of the scale that is present in India. Several studies of classroom observations from primary school have shown that currently, the focus in the early months of grade one is almost entirely on copying alphabets and numbers. Early literacy activities are usually confined to memorization of the alphabet chart. There is little focus on oral work like story telling or open-ended conversation. Drills to help children recognize letters and see how they are used together are not carried out in any systematic manner. Activities and instruction for recognizing shapes of letters and relating them to the sounds, games and exercises to locate letters and matras (phonetic and phonemic awareness) are haphazard. This is not surprising given the absence of a reading strategy supported by the government. Teachers are not trained to teach reading, nor are they given the time or resources to do it during the school day. Despite this, the momentum for change is present within the government today. According to the National Curriculum Framework of 2005:

While reading is readily accepted as a focus area for language education, school syllabi are burdened with information-absorbing and memorizing tasks, so much so that the pleasure of reading for its own sake is missed out. Opportunities for individualized reading need to be built at all stages in order to promote a culture of reading, and teachers must set the example of being 

reading.

This recognition is a critical step, but one that only scratches the surface of institutionalizing change that is needed in the teaching of reading in schools. Teachers and parents will need to value the teaching of reading and promote reading both in the classroom and at home. Government will need to train teachers and provide schools with appropriate materials to effectively teach children to read.

Room to Read's Reading Room program has been working towards this kind of change in India for the past four years by providing reading materials, conducting training for teachers, principals and community members, and supporting literacy events at schools. These efforts are described in detail below, as well as lessons learned for enhancing the program to ensure that it is having an impact on children's learning outcomes.

\section{Reading Room Program in India}

The vast majority of rural and urban government schools in India have no additional reading material beyond the government textbook. Textbooks alone fall short of providing children with relevant, engaging materials in their first few years of school. With no time for reading in the schedule, these schools find it challenging to ensure students not only learn to read, but develop a "culture of reading". In response to this gap in resources, Room to Read launched its Reading Room Program in India in 2003 with close collaboration with the state government, including Sarva Shiksha Abhiyan. The purpose of the program is to provide access to appropriate resources for children and to build capacity of teachers by establishing libraries in government and NGO run schools, thereby creating a culture of reading in the school and community. This objective is consistent with the government's interest according to the National Curriculum Framework of 2005 that states:

School libraries have been a subject of policy recommendations for a long time, but a functioning library in the school continues to be a rarity. It is important that future planning treats the library as an essential component of the school at all levels. Both teachers and children need to be motivated and trained to use the library as a resource for learning, pleasure, and concentration. The school library should be conceptualized as an intellectual space where teachers, children and members of the community can expect to find the means to deepen their knowledge and imagination.

\section{Current Approach}

Since 2003, Room to Read India has established 1,500 libraries across 21 districts in six states and has successfully secured dedicated time in the school schedule for reading. Room to Read India partners with each school for three years of direct support, during which time the library is provided with up to 1,000 books. All of the libraries are targeted at primary-age school children in grades one to five (ages $6-14$ ), and offer a wide variety of titles including folktales, fairytales, books on simple science concepts, and books on arts and crafts. In addition, each library contains posters with familiar rhymes to create a print rich environment. 
The books are carefully selected from publishers in India as well as Room to Read's Local Language Publishing (LLP) Program. The LLP Program in India works closely with the Reading Room Program to identify topics and themes relevant to the communities in which the libraries are located, and that are missing from student's reading materials. Local writers and illustrators are then commissioned to create original picture story books and other reading materials that meet the identified needs.

Beyond the three years of direct support, Room to Read India supports schools by providing them with access to LLP Program books, as well as other reading resources for teachers such as our quarterly newsletter. We plan to set up Nodal Libraries or book banks at the government's Cluster Resource Centres (CRCs), which will provide schools with a regular supply of books. Cluster Resource Centres are existing structures that provide academic support to 12-15 schools within a defined area. As a part of a commitment to build local capacity, these centers will offer teachers from the surrounding schools refresher training programs on the use of books in classroom teaching.

The Reading Room Program in India trains local volunteers from the communities to work intensively in schools, conduct activities with the students, and train school staff before eventually "phasing out" over the three year engagement period. These volunteers are called facilitators and receive a small stipend for their work. Facilitators receive trainings on: library activities to engage children with books and library resources, rationale for libraries, library maintenance, and sustainability. The facilitators are identified and managed by partner NGOs. These NGOs have been working for decades in their communities and are wellequipped to quickly identify facilitators who are qualified for the position. Room to Read India selects partner NGOs who are highly respected in their community, thereby giving Room to Read immediate validation. Over the four years that Room to Read has been working in India, this model has proven to be more cost-effective and efficient than entering communities alone.

By having a facilitator solely dedicated to running the library and conducting activities with children over three years, teachers can observe the benefits of the library and recognize its value over time. In the libraries that were established four years ago, teachers are taking over responsibilities from the facilitators and are managing the libraries and conducting activities with the children.

In addition to developing NGO partnerships, Room to Read maintains a close relationship with the government and works with SSA in all states except Delhi, where the partnership is with the Municipal Corporation of Delhi. As a result of strong government relationship, Room to Read has been able to secure time in the school schedule for library activities. By working in the schools, Room to Read has been able to build capacity of teachers and administration to manage the library and encourage its use in the classroom. Several new practices have been adopted by the schools to encourage reading. For example, children and teachers present activities during the morning assembly and regularly check out books to read at home. In some schools, the government has nominated a point teacher among existing teachers to manage the library program. Some schools make special arrangements to keep the library open during summer vacations, and teachers and children have worked together to develop new reading material. 


\section{Lessons learned}

While Room to Read India has had many successes with the library program, there have also been lessons learned. Training a facilitator to help manage the Reading Rooms has ensured that the children have access to the library resources. However, Room to Read India added teacher and principal training to the program in order to ensure that teachers take over the management of the program once the facilitators have left.

In addition, Room to Read India has had to address other issues of sustainability. In 2007, Room to Read India started supporting schools beyond the initial three years of support by providing them with access to LLP Program books, as well as other reading resources for teachers, such as a quarterly newsletter. They are planning to set up Nodal Libraries (book banks) at the government's Cluster Resource Centres (CRCs), which will provide schools with a regular supply of books. Cluster Resource Centres are existing structures that provide academic support to 12-15 schools within a defined area. As a part of a commitment to build local capacity, these centers will offer teachers from the surrounding schools refresher training programs on the use of books in classroom teaching.

The greatest challenge that Room to Read India has faced is that many children in India come to school not knowing how to read and struggle to attain literacy skills. Establishing libraries with culturally relevant books addresses the lack of resources that is evident in Indian government schools. Their training program ensures the materials are well-utilized by teachers, principals and facilitators. This model has been effective in reaching children who already know how to read and encouraging them to read more, but it does not address the needs of children who cannot read.

Room to Read India has come to recognize that in order to fully foster a "culture of reading" in schools, teachers must also teach children to read and these efforts must be reinforced at home. With so many children entering primary school with no reading fundamentals, it is clear that in order for the library program to have the desired level of impact on all children, a reading program that engages teachers and parents must be developed in conjunction with the library program.

In order to address this issue, Room to Read India has begun developing the Primary Reading Enhancement Program (PREP). The initial work on this program began in 2007, and the program will be piloted in July 2008. The details of PREP are described below.

\section{Primary Reading Enhancement Program}

In response to chronically low reading levels in India and the absence of a national reading program, Room to Read has developed the Primary Reading Enhancement Program (PREP). Having established over 1,500 libraries in eight states across India, Room to Read has developed an intimate understanding of how schools are failing to teach children to read and believe PREP addresses these failings by offering a long-term, systemic response. PREP consists of a set of teaching materials called a 'Reading Kit,' which contains locally-relevant teaching tools including conversation cards, rhyme and poem books, and picture, word and letter cards. A complementary activity book for teachers, designed by combining phonics and whole-language learning approaches, provides detailed lessons that make it easy to use for new or under-trained teachers to use. The Kit also includes a student assessment tool as 
well as a diagnostic tool for teachers to determine when and where students face difficulties in learning to read. In addition to classroom tools, parents and the government will be actively involved by supporting reading activities both in and outside the schools.

\section{Rationale and Objectives of PREP}

PREP is based on the belief that in order to create a culture of reading within schools:

1. Students need to have access to engaging materials that effectively support their learning;

2. Teachers need to be trained to teach reading;

3. Schools need to provide time for the teaching of reading;

4. Parents and the community need to support and supplement the teaching of reading; and

5. Government needs to commit resources to the teaching of reading.

The long-term vision is for schools to value a "culture of reading" and thus consider themselves to be "Reading Schools". Room to Read has defined a "Reading School" as a school in which:

- Reading is an integral part of the overall language strategy

- Reading is both a structured and unstructured activity at school

- Parent and community participation in the teaching of reading is valued

- Teacher-training to teach reading is institutionalized

- Remediation is offered to students who need additional support in learning to read

- There is a child-friendly environment

- A student-centered approach is valued in the teaching of reading

- A variety of books and reading materials are used frequently both in and out of schools to teach reading and other subjects

- In areas where the home and school languages different significantly, schools will ensure children transition to the school language in the early grades

Based on current realities in India, such a school would require significant behavior and policy changes by teacher, school administration, communities and within state and national governments. Teachers would need to value the teaching of reading and encourage parent and community participation in the teaching of reading. They would need to rely not just on textbooks but on supplementary reading materials, and even create locally-relevant materials themselves. They would need support from the government to teaching reading in the form of advising, training and time allocation in the schedule. Parents and communities would need to develop a sense of ownership in the teaching of reading in schools. This might mean regular, active participation in the schools, and it would definitely mean facilitating reading at home. From the government, supporting "Reading Schools" would mean including the teaching of reading in its curriculum from the very first day of school. It would mean supporting pre-service and in-service teacher training in reading instruction. These are the long-term outcomes Room to Read is working toward with the development of PREP.

\section{Approach and Materials}

The two main camps in teaching reading are the phonics approach and the whole-language approach (using extensive reading, pictures and contexts to learn to read). Consistent with 
current research trends, PREP adopts a "balanced" or "mixed" approach that combines both phonics and whole language activities. The program begins using a whole language approach which allows children to actively participate using their own vocabulary, rather than words dictated from textbooks. It then shifts to a more phonetic approach like that of the textbook, closely examining letters and words. Listening, speaking, reading and writing are integrated in nearly all lessons. It follows the principal of "spiral learning" such that the same stories and content is revisited through the intervention at different stages of learning and with activities of varying degree of difficulty. Not only is this pedagogically sound, but using the same materials at different stages increases the Reading Kit's cost-effectiveness.

The Kit is comprised of the following materials:

1. Picture Conversation Charts. These charts depict local scenes familiar to the child and likely not found in their textbooks. Children are therefore more likely to participate in a conversation using words familiar to them. The kit contains conversation cards of different states, therefore exposing children to the way of life in other parts of India.

2. Rhymes and Poems. Rhymes and poems help children to develop systematic anticipation. They contain linguistic patterns that are easy to memorize and can be written on paper and posted on the wall to help create a print-rich environment. The rhymes and poems are also locally-relevant.

3. Picture Stories (same stories with and without text). Teachers can show and read these stories to kids. Later, the kids can work in small groups to re-tell the stories, moving towards more structured and decoding reading approach.

4. Picture and Word Cards. These cards can be used to identify words in the conversation charts and to match words to pictures. As children move from one stage to another, these cards will enable them to construct words and sentences and to make their own stories.

5. Collection of Graded Story Cards. Graded story cards allow for children of different levels to participate in this exercise at the same time. Children can advance through the story cards, giving them a sense of accomplishment.

6. Activity Book for the School Teacher. The activity book provides teachers with a series of scripted questions and lessons to use with the kit. Novice teachers can easily follow the lessons directly from the book, while more experienced teachers can use it to generate ideas. For example, it contains open and closed-ended questions, skillbased exercises and games, puzzles, and pre-writing and writing exercises. Activities are designed for large groups, small groups, pairs of students and individual students. The activity book also provides the teacher with the rationale behind activities and the short term and long term objectives as well as explicit connection between the kit materials and the textbooks.

7. Reading Assessment Tool. This tool will provide teachers with feedback on the progress of each student. It is designed to be administered at the beginning and the end of the year, informing the teacher if the student is prepared for the next grade and providing Room to Read India information on the effectiveness of the intervention. 
The Reading Kit materials both complement and supplement the textbooks. They reinforce and add to the desired competencies of the curriculum. They are also relevant to children from all states. The conversation charts, for example, depict scenes from different states within India. Furthermore, the teachers are trained and the activity book contains lessons to develop locally-relevant teaching materials. By associating print with images familiar to the child (those of the textbook are not necessarily familiar to the child), children simultaneously decode and construct words and later sentences. It should also be noted that for children across Delhi, Rajasthan and Uttarakhand, there are only minor variations in their home languages, which are dialects of Hindi. Therefore, language-adaptation of the Kit is not necessary.

\section{PREP Pilot}

The PREP pilot will take place in the three states of Delhi, Rajasthan and Uttarakhand. PREP will be implemented in a total of 180 schools over the two-year pilot: 150 schools with a Room to Read library and a Room to Read facilitator and 30 schools with neither. This approach will help Room to Read to understand the issues PREP might face when expanded to areas without a Room to Read presence.

The objectives for the pilot are:

- Students will read with improved fluency and accuracy

- Students will show an increased interest in reading

- The government will recognize the importance of teaching reading as part of the teaching-learning practice

- Teachers will recognize the importance of materials other than textbooks to teach reading, including the Reading Kit

- Teachers will be able to identify areas of difficulty in students learning to read

- Parents and communities will be acquainted with PREP and classroom changes related to the teaching of reading

- Parents and communities will be aware of the opportunity to participate in the teaching of reading at schools

- Government teacher-support structures will recognize PREP as a potential solution to effectively and efficiently teach children to read

In order to reach these objectives, Room to Read India will focus on activities with children, parent and community participation, government participation and advocacy, and student assessment.

\section{Activities with Children}

In the 150 schools with Reading Rooms, facilitators will be the primary implementers of PREP in Year 1 but will be phased out during Year 2 in place of teachers. As described above, facilitators are individuals from the community who have completed at least grade 10 (some have a college degree). They have been working in the target schools since July 2007 as part of the Reading Room Program, setting up the library and conducting activities with the children. In the upcoming year, they will implement the reading program using the Reading Kit and library materials and conduct regular activities associated with the Reading 
Room Program. In addition, they will work with parents and the community to generate interest in support for PREP.

\section{Parent and Community Participation}

Parents and the community play an integral role in supporting children's reading by participating in activities at the school as well as reinforcing them at home. From the beginning of the PREP pilot, parents and communities will have the opportunity to learn about the program - both what their children will be learning in school as well as strategies for their active participation in, and reinforcement of their children's learning.

Room to Read will share the results of the baseline assessments with parents and also share strategies for improving the reading abilities of their children. They will be invited to participate in organizing Parents' Days, where they will have the chance to witness their child's progress. They will be asked to participate in school activities such as story-telling or reading a book. Room to Read will also encourage the trend already taking place in India of parent participation in school activities over summer break. By engaging with parents through these activities, they will develop a sense of ownership in their child's reading learning both in and out of school.

\section{Government Participation and Advocacy}

Room to Read has a history of strong partnerships with state governments. By maintaining this close working relationship with governments, Room to Read is more readily accepted and valued by schools and teachers. This is also critical for the long-term sustainability of our work. Room to Read's government participation and advocacy strategies for PREP are based on these beliefs.

Room to Read will engage with the Delhi, Rajasthan and Uttarakhand governments from the beginning of the pilot and will have ongoing interaction with them throughout the project. We will share information with state and local-level governments through regular meetings and reports.

Our government participation and advocacy strategy is not only information sharing, but we will also actively and regularly solicit feedback from the government to inform our model. As such, we anticipate that our final model will address potential concerns and considerations of governments, and will therefore be well-positioned for a large scale roll-out following the pilot.

\section{Student Assessment}

There are three main tools for student assessment in the PREP model:

1. An assessment tool used for baseline, mid-term and final assessments of students' reading abilities. This tool is in draft form and we plan to hire an assessment expert to ensure it captures the information needed to determine a student's reading level

2. A diagnostic tool to help teachers identify where students are having difficulties learning to read. This tool will be administered by teachers to students who are not progressing or who are having a particularly difficult time learning to read. It will 
pinpoint a particular skill or set of skills a student is having trouble acquiring so that the teacher can tailor his/her teaching appropriately. The tool will be developed by a local consultant.

3. Continuous assessment. As part of the structured lessons in the activity book, teachers will be presented with specific activities that can be used for continuous assessment. Information from these assessment activities will not only inform a teacher about the progress of an individual student, but also about the progress of the class as a whole.

\section{Anticipated Challenges}

PREP has great potential to have an impact on the culture of reading in government schools in India. However, as with any educational intervention, there will be challenges. These include:

- Working with teachers that may be resistant to change.

- Children's irregular attendance, which makes it difficult for teachers to build upon skills.

- Ensuring participation from parents that have competing priorities.

\section{Conclusion}

Room to Read is committed to developing a culture and habit of reading among children. From libraries to trainings and now to a structured reading program for students and teachers, Room to Read India has developed a locally-driven approach to teaching young students to read in their first years of school. The PREP model is based on the belief that in order to create a culture of reading within schools, students need to have access to engaging material, teachers need to be trained to teach reading and to use this material, parents and communities need to support reading both in and out of schools and government needs to commit resources, including time, to the teaching of reading.

Room to Read will continue to work globally to develop library programs that are an effective in addressing the literacy gaps in developing countries. The interventions will look different in each country, and will be based on locally identifies needs.

\section{References}

Krolak, L. (2005). The Role of Libraries in the Creation of Literate Environments. Hamburg, Germany. UNESCO Institute for Education.

Lonsdale, M. (2003) Impact of School Libraries on Student Achievement. Australian Council for Education Research.

Rosenberg, D. (1998). Getting books to school pupils in Africa-Education Research Paper No. 26. Department for International Development

\section{Statement of Originality}

This statement certifies that the paper above is based upon original research undertaken by the author and that the paper was conceived and written by the author(s) alone and has not been published elsewhere. All information and ideas from others is referenced. 


\section{Photos}

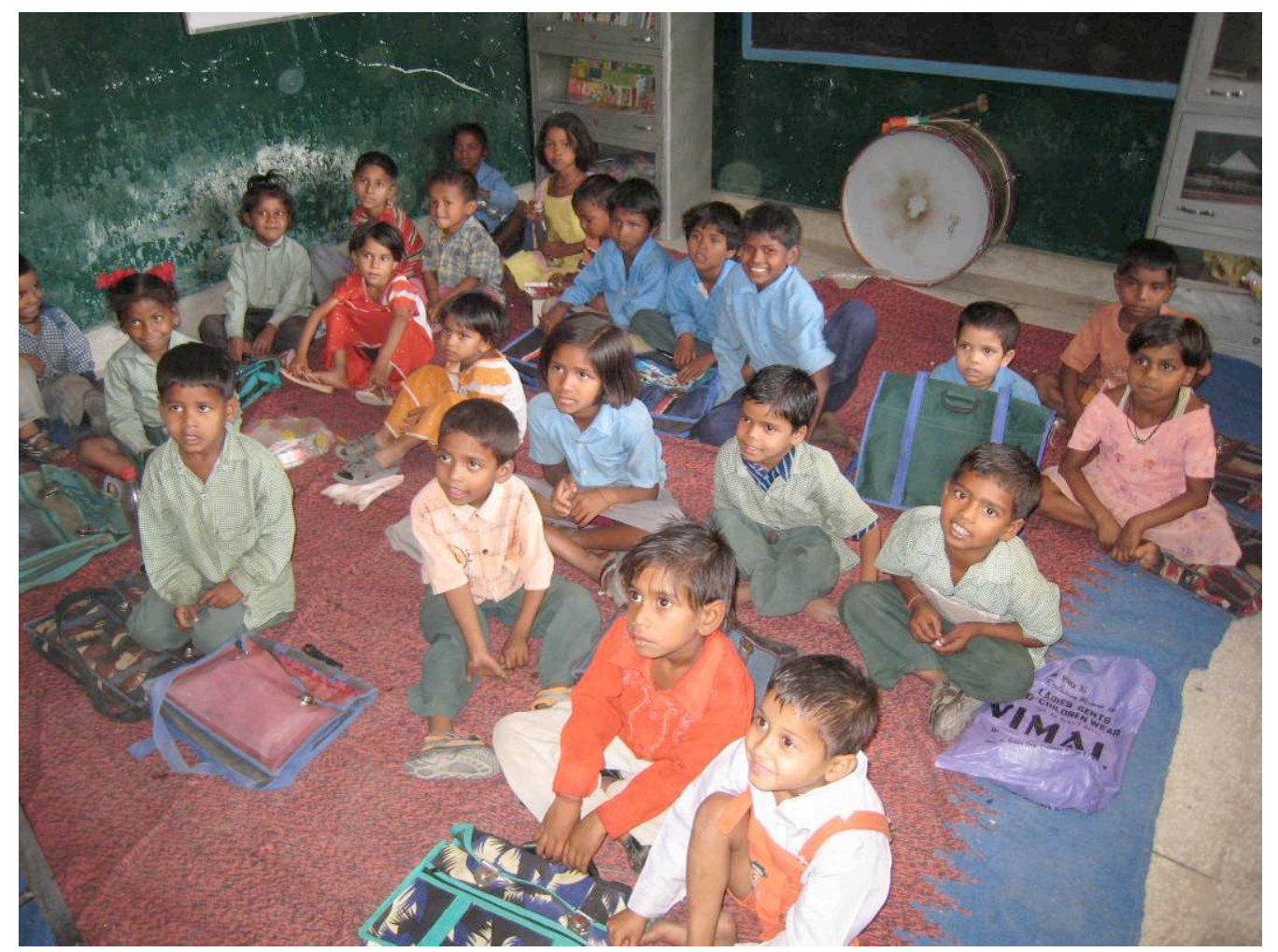

Children in a government school in Delhi.

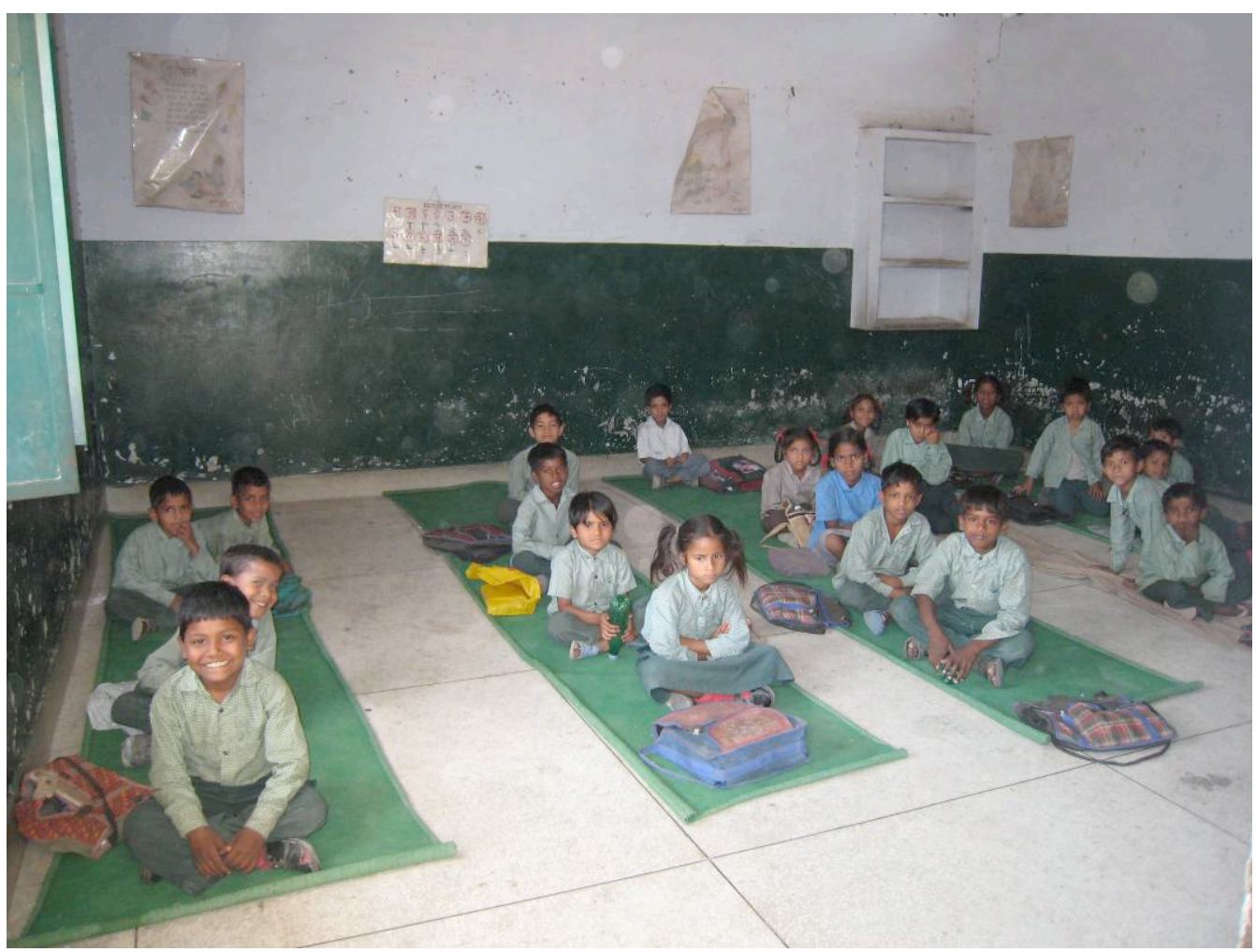

Many schools in Delhi do not have furniture or print on the walls. 


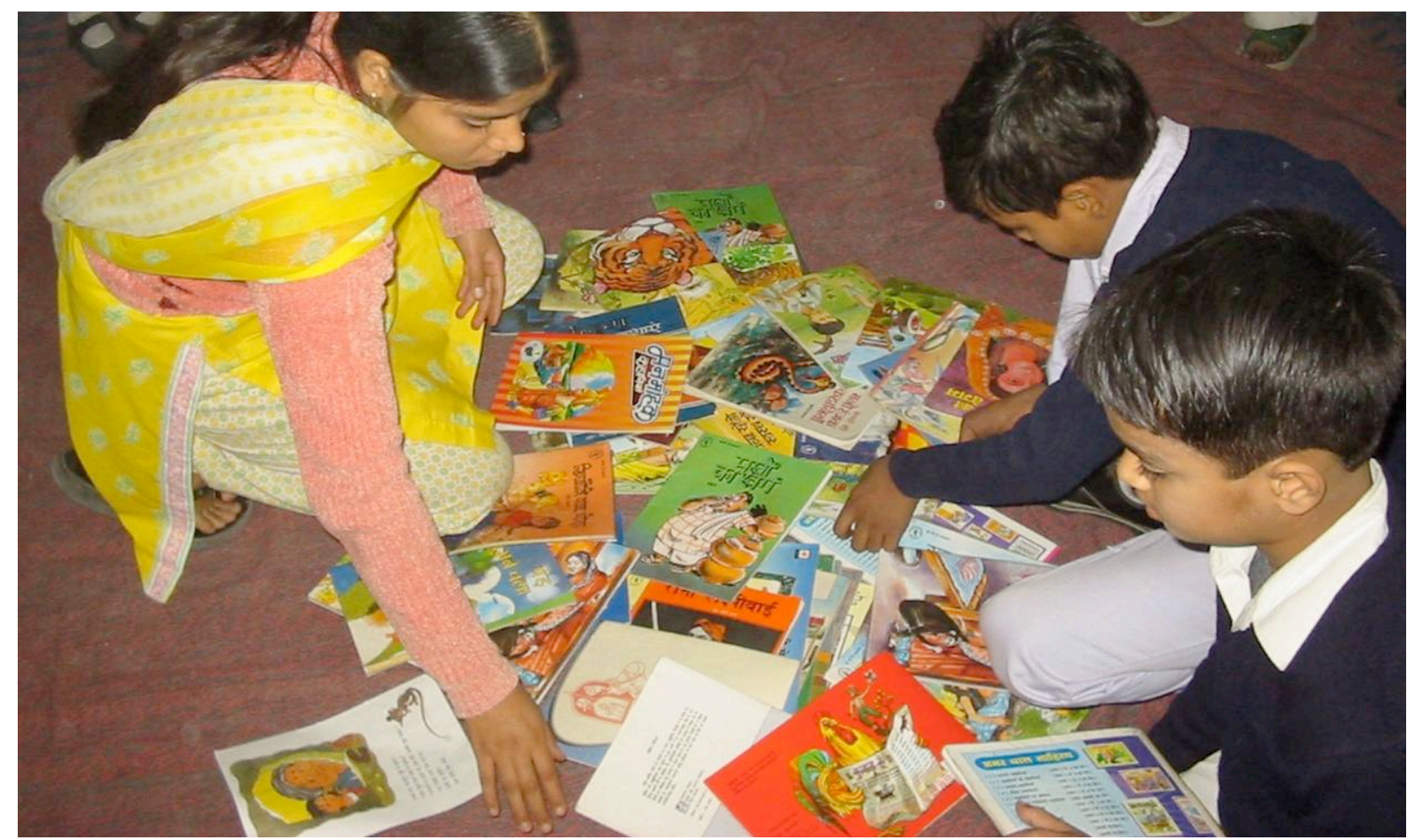

A facilitator assisting children in the selection of books.

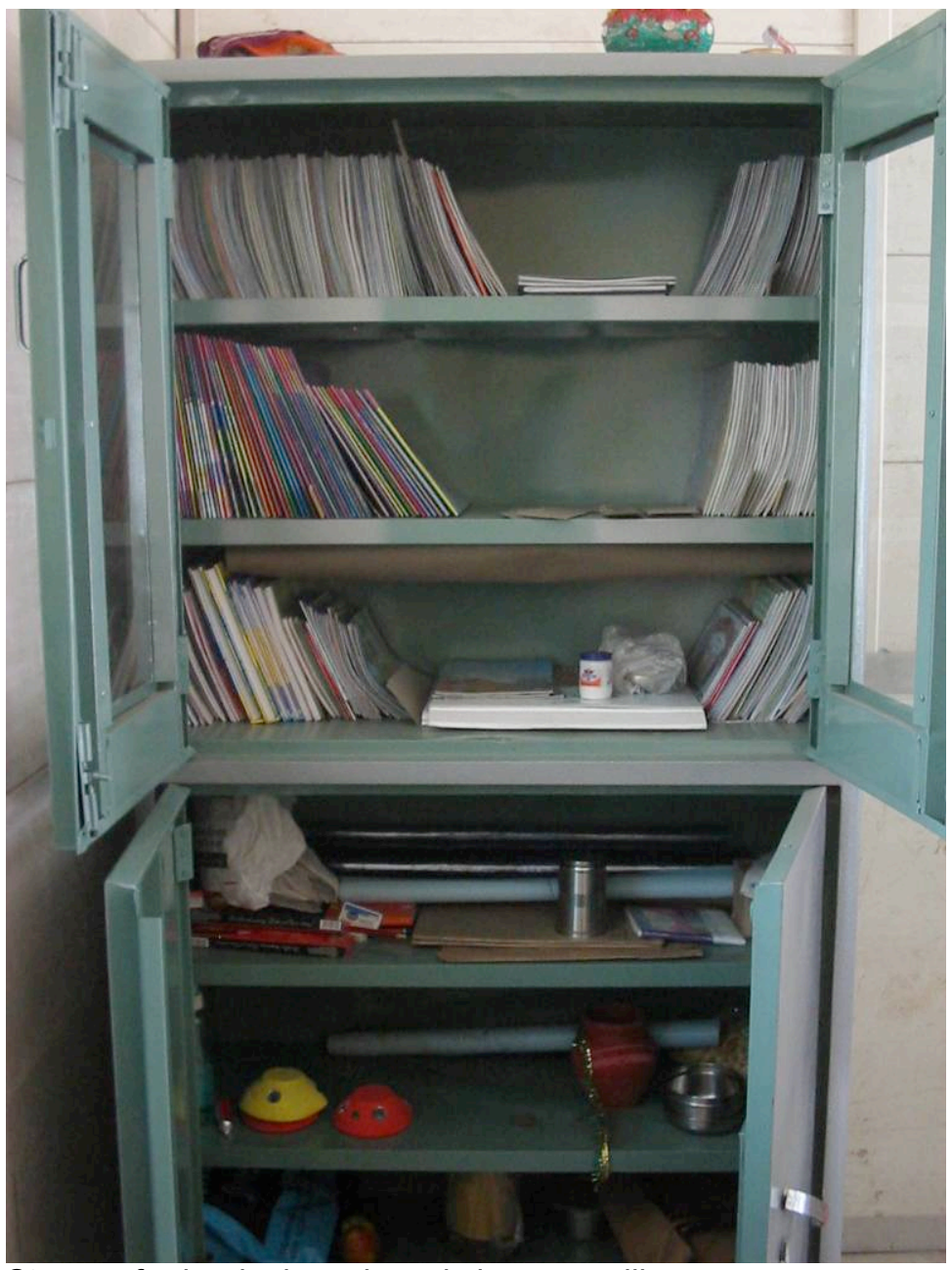

Storage for books in a shared classroom library. 


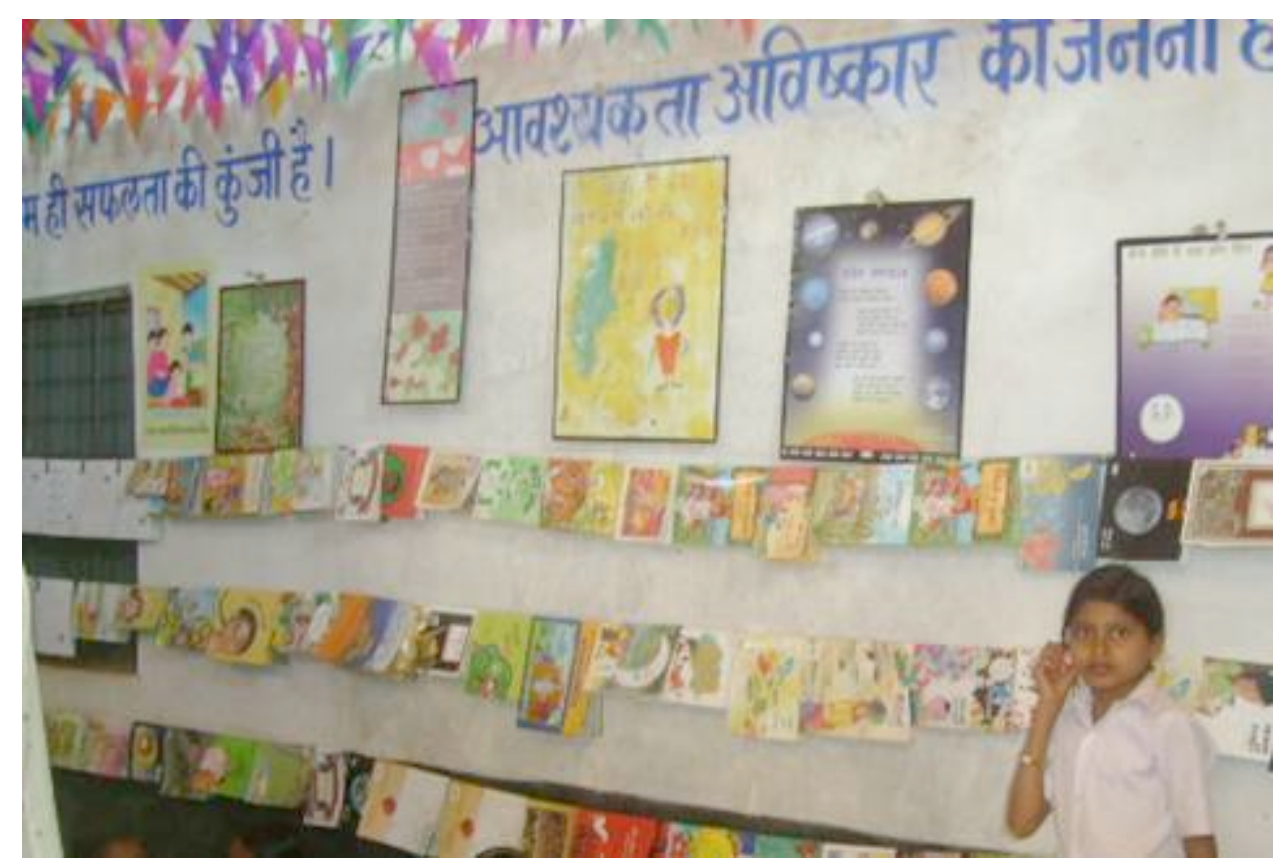

Creative ways of displaying books without furniture.

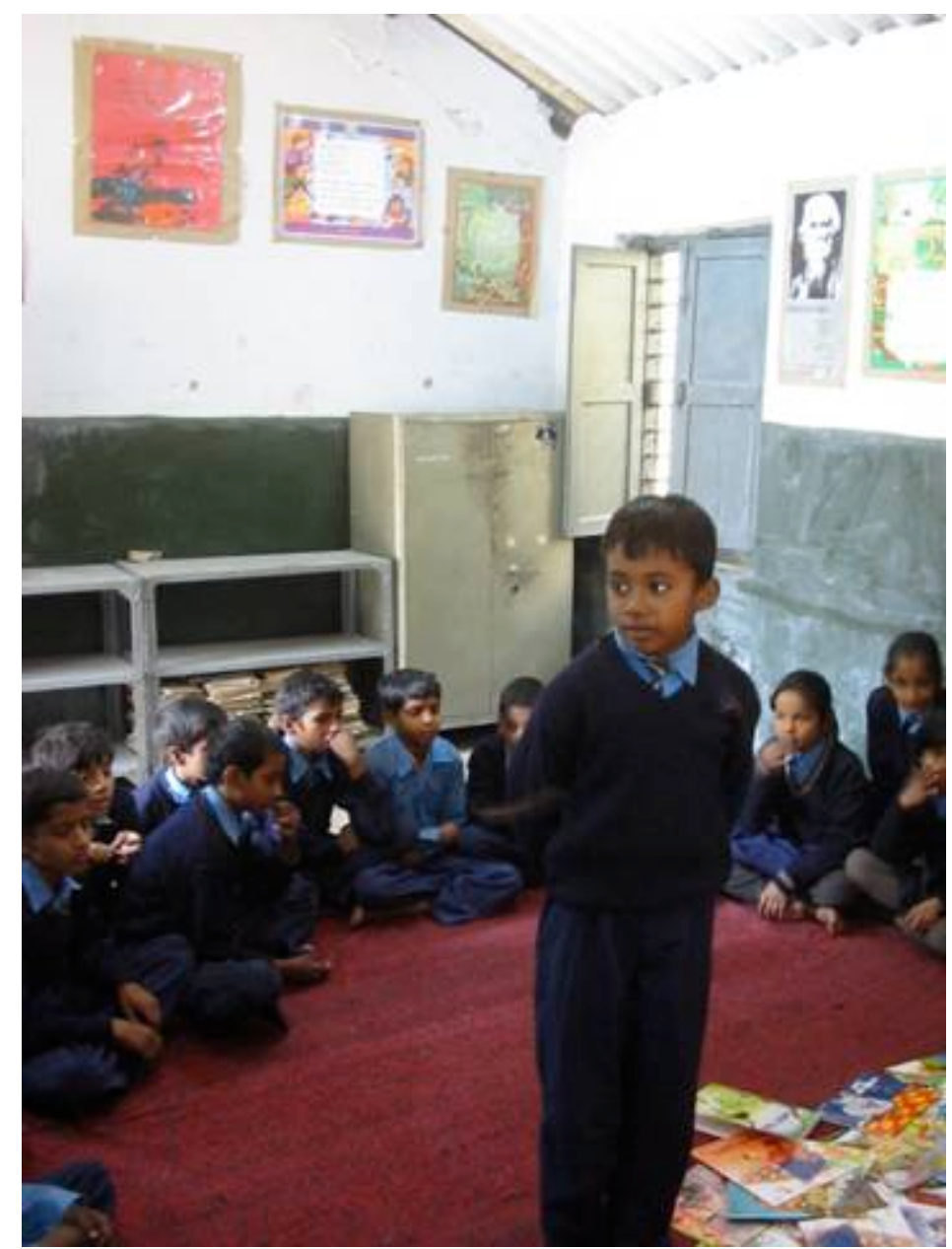

Activities in a Room to Read library. 


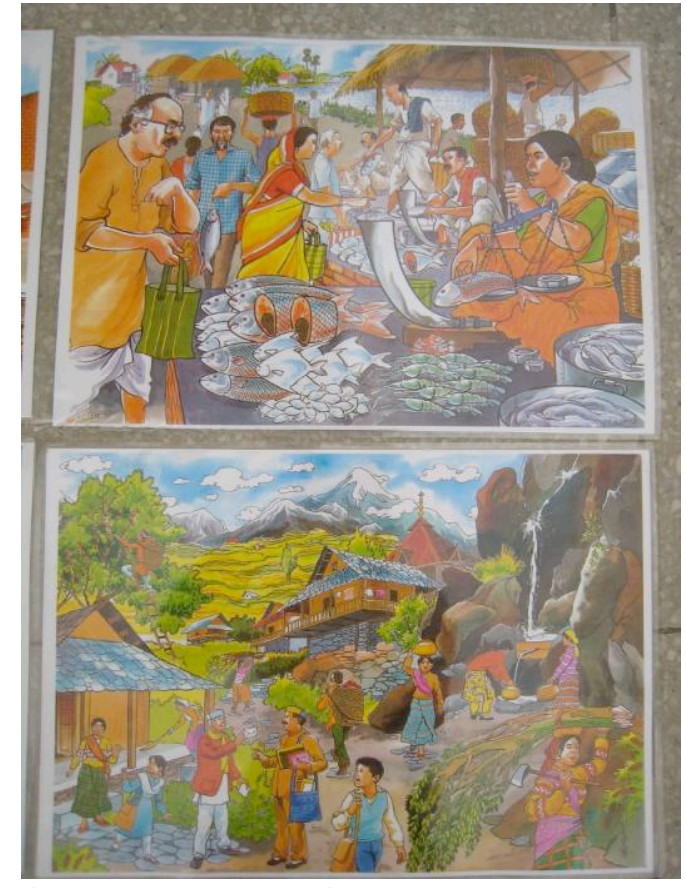

Conversation chart from PREP.

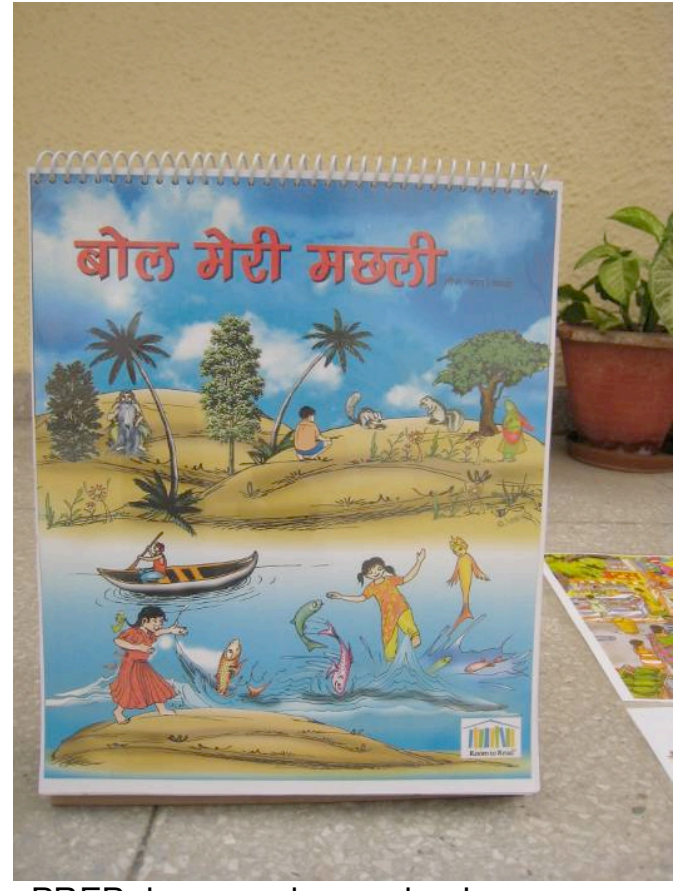

PREP rhyme and poem book.

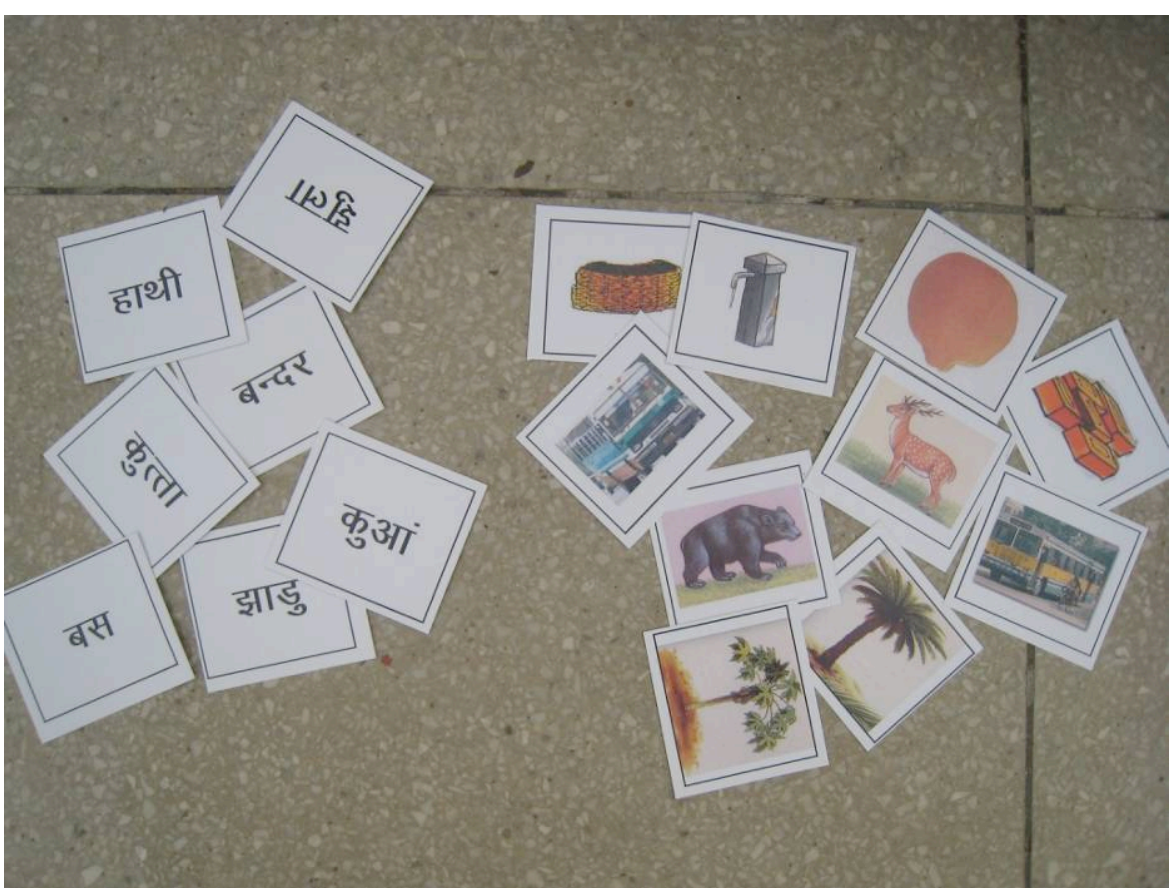

Picture and words cards from PREP. 